[Zepke, N., \& Leach, L. (2006). Improving Tertiary Student Outcomes in An Evidence-based Accountability Policy Framework. New Zealand Annual Review of Education, 15, 23-43]

\section{Improving Tertiary Student Outcomes in An Evidence-based Accountability Policy Framework}

\author{
NICK ZEPKE AND LINDA LEACH
}

\section{Abstract:}

Tertiary student retention, progression and achievement have become major policy issues in New Zealand, and the English-speaking world generally. Both the human and financial costs of non-completion have led to policy settings dedicated to improving student outcomes. After briefly sketching policy developments in the United Kingdom, Australia and the United States, the article examines the New Zealand government's emerging policy framework for improving student outcomes. It suggests that concern for student learning and success is justified, but questions some of the underlying assumptions behind the policies. These, the article argues, focus on system-wide accountability using crude statistical indicators that can lead to sanctions. The paper uses retention research from overseas and New Zealand to test both assumption and criticism. The article suggests that evidence does not support a generic and punitive approach to improve student outcomes. It suggests a reframing of both accountability and research evidence to produce an alternative approach to student outcomes policy.

$\mathrm{I}^{\mathrm{m}}$

mproving tertiary student outcomes by increasing retention, persistence and completion is both a major policy goal and research focus in many developed countries (Yorke \& Longdon, 2004). According to the New Zealand Ministry of Education, about one-third of tertiary spending "is wasted on people who do not complete their qualification" (Gerritson, 2005, p. 1). This is similar to the level of attrition in Australia (McInnis et al., 2000) and the United Kingdom (Yorke, 1999). Rates of early departure are even higher in the United States, where Braxton (2000) reports that 45 percent of college and

\section{Nick Zepke and Linda Leach}

university students depart before completing their qualifications. Governments increasingly expect improved learner outcomes for money spent on their tertiary education. Data on "wastage" highlight their concerns. For example, in the United Kingdom, Yorke (1999) estimated that early student departure cost 100 million pounds a year. In New Zealand, a recent Ministry of Education report (Scott, 2005) showed that, from 1998 to 2003, students who dropped out in their first year of study consumed 33 percent of the equivalent full time student (EFTS) funding. Consequently the government is taking great interest in how well institutions retain learners. Recent policy documents signal increasing accountability for improving outcomes by ensuring that students who enrol in programmes are retained until they complete their qualification (New Zealand Government, 2002 \& 2005; Ministry of Education, 2004).

However, as Scott (2005, p. 4) observes, rates of qualification completion are only one indicator of the value a country is getting for its investment in post-school education and training. It is not the only measure, or even the most important. It is also important to recognise that these policy developments ignore key issues - the definition of completion and whether non-completion is necessarily a negative outcome. Yorke (1999), McInnis et al. (2000) and Scott (2005) suggest that many students take time out and complete qualifications over a longer period than expected, complete different qualifications, or complete in other institutions. But they are lost in the analysis of retention data. There is also an argument that, for some students, withdrawal is a positive outcome, for example, when they leave to take up employment opportunities. Arguably they could be seen as "successful dropouts" (McInnis et al., 2000, p. 9). To that extent, if a high proportion of students do not complete their qualifications, this cannot necessarily be read as system wastage (Scott, 2005, p. 14).

Nevertheless, how to improve student outcomes by improving retention and completion has been well researched. Major syntheses have been completed over the last three decades, primarily in the United States (Tinto, 1975, 1988, 1993; Pascarella and Terenzini, 1991, 2004; Astin, 1993, 1997) but also in Australia (McInnis et al., 2000) and New Zealand (Prebble, Hargraves, Leach, Naidoo, Suddaby \& Zepke, 2004). Major retention studies have also been completed in the United Kingdom (Martinez \& Munday, 1998; Yorke, 1999). Until recently, New Zealand literature on retention was sparse. But research activity has picked up markedly since the turn of the century (Grote, 2000; Anae, Anderson, Benseman \& Coxon, 2005; Wilson, 2002, 2005; Dewart, 2003; 
Trembath, 2004; Scott, 2005; Coltman, 2005; Zepke \& Leach, 2005; Zepke, Leach \& Prebble, 2005). Most New Zealand studies have followed an integration discourse credited to Vincent Tinto (1993). This suggests that retention improves where institutions successfully integrate students socially and academically into their prevailing cultures. A few diverge from this integrationist stance. Purnell (2002) acknowledges Tinto's contribution, but explains her research in terms of Nicholson's transition cycle. Zepke and Leach (2005) and Zepke, Leach and Prebble (2005) add an adaptation discourse to Tinto's integrationist explanations. Here institutions attempt to recognise, value and accept learners' diverse cultural capital by adapting their cultures to meet diverse learner needs. Bennett and Flett's (2001) research into the role of Maori cultural identity in student success mirrors this adaptation discourse. Fraser (2004) reports another approach - ensuring students have the necessary academic skills upon entry.

This article examines policies developed to improve student outcomes such as retention and achievement. It asks whether they work, in New Zealand and elsewhere. After briefly sketching international policy developments, we examine the New Zealand government's emerging policy framework. We agree that concern for improving learner outcomes is justified and, indeed, overdue. But we question some of the assumptions underpinning the policy framework. Specifically we critically examine assumptions about the nature of accountability and evidence-based policy and practice, two keystones in current policy settings. These assumptions have produced policies based on simple statistical indicators that can lead to financial sanctions. We use the results of international and New Zealand research to test both the assumptions and our critique. The evidence, we suggest, does not support a generic and punitive approach to improve tertiary student outcomes. Finally, we suggest that reframing both accountability and the nature of research evidence will produce an alternative approach to student outcomes policy.

\section{The Policy Scene}

While countries develop differentiated education systems and policy frameworks, many common policy directions in western countries can be identified. This is due to the ascendancy during last century of neo-liberalism, an ideology labelled "turbo capitalism" by Finger \& Asún (2001). It spread throughout the developed world by what Edwards \&
Usher (2000) call policy migration, a by-product of globalisation. Neo-liberalism characterizes tertiary education as a market place, where institutions become providers of marketable knowledge and skills, as well as supplying a marketable service (Codd, 2005). They create efficient "autonomous choosers"- people who have useful skills for the market place culture and use them to exercise choice (Peters \& Marshall, 1996, p. 40). But a market place governed solely by choice is chaotic, leaving governments that have continued to fund tertiary education unable to exercise "steerage" (TEAC, 2001). In order to enable the market to function while maintaining control, governments borrowed from neo-liberal theories. Ball (1998) itemizes neo-liberal approaches as performativity, public choice theory and a new managerialism. Educational institutions were to be efficient, competitive and accountable to the public. Accountability was theorized as a contract between the government funder and its agents, where the agents, in order to receive funding, agreed to meet preset targets. Failure to do so meant a penalty was imposed. Statistical indicators often measured whether accountability requirements were met (Yorke \& Longdon, 2004).

While the hard core of neo-liberalism has been softened in some jurisdictions, it has not been replaced, and policy frameworks retain many of its features. Certainly, the neo-liberal version of accountability has remained a key factor in public policy in Australia, the United Kingdom and the United States, for example. Yorke and Longden (2004) suggest that retention, attrition and completion statistics are seen as particularly useful performance indicators. They are expected to permit performance assessment using objective data, benchmarking against expected values, against other institutions, against other national systems and, when published, provide information to assist consumer choice. Countries such as the United States, the United Kingdom and Australia have adopted retention as one of the statistical indicators used to assess institutional performance. Higher education in the United States is largely a state matter. States monitor institutional performance using indicators. Retention and success rates are considered important indicators of state and institutional performance with some states coupling retention rates to funding (Yorke \& Longden, 2004). In the United Kingdom, retention indicators have been published since 1999. The then minister for the sector expressed her expectations that those institutions with poor retention rates would make serious efforts to improve them (Yorke \& Longdon, 2004). In Australia, the federal 
government uses performance criteria to measure student success. Rather than using degree completion as an indicator, a measure called a Student Progress Unit (SPU) has been developed to measure student success in completing the subjects for which they first enrolled (McInnis \& James, 2004).

New Zealand's education policy often mirrors international frameworks. In the 1990s it was similarly framed in neo-liberal terms. Successive Labour-led governments since 1999 have moderated this ideological orientation. A "third way" is expected to avoid the extremes of both neo-liberalism and the welfare state by emphasizing "social inclusion, pluralism and democratic involvement within an active civil society that supports a market economy" (Codd, 2002 p. 32). Education stands very high on the list of "third way" priorities. It plays a key role in linking economic progress to social cohesion. But as a number of New Zealand commentators have argued, educational policy owes more to economic aspirations than concerns for social inclusion (Kelsey, 2002; Olssen, 2001; Codd, 2005). A tertiary education strategy document, outlining six goals to 2007, illustrates this (New Zealand Government, 2002). The goals are to achieve economic transformation, social development, Maori development and advancement, environmental sustainability, infrastructural development and innovation. They pursue the social benefits of tertiary education, but economic goals seem to be in the ascendancy, as prosperity and competitiveness in global markets are strongly linked to national aspirations. For example, while Maori cultural aspirations are acknowledged as goals of tertiary education, capacity building is expected to increase relevance and integration of the system by aligning closely with national goals, linking with business and the wider global community and developing partnerships with Maori. Research and innovation are seen as key drivers of modern economies and will enable the achievement of economic as well as social goals (New Zealand Government, 2002).

Regular Statements of Tertiary Education Priorities support this high level Strategy document. The latest, The Statement of Tertiary Education Priorities (STEP)2005-2007 (New Zealand Government, 2005), continues to balance economic and social priorities, although the balance tilts further to the economic. The emphasis is on value for money spent, relevance to national goals, increased quality of provision, increased responsiveness to learners, improved global linkages, stronger linkages with business and other external stakeholders, greater collaboration, more future focus and a culture of optimism and creativity; in short a New Zealand that is "more innovative, more skilled, more productive, more prosperous, and with increased overall well being (p. 3). It is organized into four interrelated themes. One of these is of special relevance to this article. It emphasises excellence in teaching, learning and research. This theme is about "ways that tertiary education organisations can demonstrate that students and learners are achieving good outcomes, and that research is of a high standard" (p. 6). It wants to combine the efforts of tertiary educators, organisations and central agencies in improving student outcomes. The STEP introduces accountability measures so that tertiary providers and central quality assurance bodies "... sharpen the focus of their quality assurance arrangements on effective teaching and learning ... prioritising improved learning outcomes as part of quality assurance processes" (p. 10). The funding system will be directly linked to learner achievement. "As part of a suite of instruments focused on quality, a "performance measure" will be introduced into Student Component funding" (p. 11). This identifies poor performance, and leads to improvement agreements, but where poor performance persists it will be used to reduce funding.

This "performance measure" was initially given shape in the Interim Funding Policy (Ministry of Education, 2002) which announced new funding arrangements to improve student outcomes by increasing retention and completion rates. Retention and completion data, collected by the Ministry, would be used to indicate whether government's quality objectives were being met. A retention rate below 50 percent would trigger a quality audit to investigate reasons for the low retention rates and lead to a decision of whether or not funding approval would be withdrawn. A Technical Working Group (2003) was tasked with producing performance indicators that would be acceptable proxies for all learners and all institutions. It proposed three indicators. One addressed retention, another successful course completions and a third, quality delivery as perceived by graduates in a graduate experience questionnaire. It also set benchmarks that had to be met by institutions: 60 percent for completions, 75 percent for retention and 90 percent for positive mean scores on the questionnaire. It proposed (p. 9) that in order to qualify for performance funding a provider must report satisfactorily against all indicators. A process of dialogue would ensue if the institution failed on one or more indicators. If indicators didn't improve the following year, 5 percent of student component funding would be at risk. 
Subsequently a Sector Reference Group (2004) considered this report. It accepted the three indicators as relevant for all institutions and learners. It agreed that a penalty of 5 percent of student component funding was a reasonable penalty for poor performance. It rejected, however, benchmarking as a "one size fits all" approach to a complex issue. It recommended a process called a "performance dialogue" (p. 4) between the Tertiary Education Commission and the lowest performing 5 percent of providers. This dialogue would involve a remedial action plan, auditing of progress towards improvement and, as a last resort, the imposition of funding penalties. In October 2004 the Associate Minister of Education (Tertiary Education) announced the policy in a media statement:

The Tertiary Education Commission will also collect information on course retention rates and successful course completions at each funded provider ... (E)ach year the weakest-performing two public institutions and thirteen private providers will be required to develop remedial action plans. If their results don't improve the following year, a portion of their tuition funding will be placed at risk - 3 percent in the first year, rising to a maximum of 5 percent. (Maharey, 2004)

As in the United States, the United Kingdom and Australia, retention has become a proxy for assessing quality of provision. While benchmarks have been rejected as accountability standards, norm-referenced assessment has become the means of measuring accountability. The assumptions underpinning this policy are examined in the next section.

\section{Accountability and Evidence-Based Policy}

Policies like these do not emerge from thin air. They are developed on the back of assumptions about how the world works or ought to work. Accountability is one of their anchoring ideas. Charlton (2002) sees accountability as having two relatively distinct meanings, one general and the other technical. It can refer to the general (mutual) responsibility that people have for each other, but it can also be tied to performances that can be audited. The latter meaning seems to have its origins in the technical world of accounting. Biesta (2004) suggests that an "accountability culture" has emerged in the western world. He argues that this is used as a system of governance that results in an audit society. He links the emergence of the audit society to neo-liberalism and the marketisation of education. This has re-conceptualized the relationship between government and citizens from the political to the economic. It is a relationship between consumers and providers, with government as provider and educational institutions as consumers at one level. At another level tertiary institutions become providers and their students, consumers. The role of government is to create and manage this complex, layered market by providing the conditions, laws and contractual regulations necessary to create and maintain it (Olssen, 2001). This technical, audit-focused meaning of accountability underpins the policy framework governing student outcomes such as retention, attrition and completion in New Zealand as elsewhere.

Policy-makers working within the accountability culture face the challenge of giving teeth to accountability regimes. One way is to link policy to stated, expected outcomes. Here, to be accountable is to demonstrate that certain outcomes have been achieved. The question of evidence then arises: what evidence will show that outcomes have been achieved or improved? The evidence is expected to be objective, scientific and therefore tends to be quantitative. Often this requires demonstrating by audit that certain numerical targets have been achieved. This seems to be the way retention and completion rates in the United Kingdom are assessed. Accountability, using universally applied targets, must be met by all, regardless of differences in mission, make-up or organization, resulting in a "one size fits all" approach. The New Zealand case eschews the targets, but requires outcomes that must be met if a threatened financial penalty for the lowest performing institutions is to be avoided. The evidence used to rank institutions is captured in returns provided by them. These data are simple numerical counts of retentions, completions and student satisfaction. They do not probe the reasons for either good or poor performance.

Underpinning such policies are a number of assumptions about evidence. One is that numerical counts provide transparent, fair and objective information about outcomes. Another is that scientific evidence will also provide the information from which improvements can be made. A third assumption is that evidence must be practical, informing both policy-making and practice. This focus on practicality has given rise in the United Kingdom to the mantra "what matters is what works" (Sanderson, 2003). Experimental research or syntheses of such research are regarded as the best evidence suited for this purpose. Petrosino et al. (2001), for example, describe an extensive international 
community of scholars, the Campbell Collaboration, which engages in syntheses of educational research designed to assist both policy-makers and institutions. The idea of evidence-based policy seems to have originated in medicine in the early 1990s (Black, 2001) and translated into education at a slightly later stage in both the United Kingdom (Davies, 2005) and the United States (Petrosino et al., 2001). In New Zealand too, evidence-based policy plays an important role. Since 2003 three Statements of Intent have been published (Ministry of Education, $2003,2004,2005)$. Evidence-based policy and practice is apparent in all three. The Statement of Intent 2003-2008 includes a goal to "promote evidence-based decision-making" (p. 6) as one of five critical areas for action. By 2004 the Ministry was proclaiming "In the last few years the Ministry has invested heavily in developing indicators and information, and commissioning research to strengthen evidence-based policy and practice" (Ministry of Education, 2004, p. 16). In the third, the Statement of Intent 2005-2010, the use of evidence to strengthen policy and practice and improve student achievement is embedded in both text and diagrams. The United Kingdom mantra of "what works" also appears:

Educational policy and practice must align to improve student achievement. It must be informed by, and respond to, information about what works. The increased evidence leads to a clearer transparency and understanding of the critical influences that operate throughout the education system. The analysis of evidence to inform policy and practice creates a way to drive continuous improvement. (Ministry of Education, 2005, p. 13)

An "evidence-based approach to teaching" is also embedded (p. 18). These Statements of Intent picture a comprehensive, evidence-based process linking high level goal setting and direct remedial intervention. Such a process is visible in the development of policies regarding improvement of student outcomes such as retention, progession and completion. The Ministry commissioned a major research synthesis (Prebble et al., 2004) on institutional effects on student outcomes, conducted its own research into completions (Scott, 2005) and, the Government, through the Teaching and Learning Research Initiative (TLRI), funded a New Zealand study on retention (Zepke et al., 2005).

\section{Does Evidence-Based Accountability Work?}

If the theoretical environment surrounding student outcomes policy is relatively clear, whether such policy works is not so clear. In this section we examine whether evidence-based policy and accountability can improve student outcomes such as retention and completion. We consider arguments and evidence about such policy generally, including findings from outcomes research conducted in New Zealand.

Evidence-based policy has many supporters among researchers (Fitz-Gibbon, 1996; Coe et al., 2000; Davies \& Nutley, 2001; Petrosino et al., 2001). With slight variations, the arguments in favour suggest that, in an age where the stakes associated with accountability are extremely high, policy needs to be based on the best evidence available. Best evidence is scientific and quantitative. Where evidence emerges from experimental research or from systematic syntheses of such research, it is possible to identify "what works" and inform both policy-makers and institutions. Proponents recognize many technical challenges faced by researchers, but claim the benefits outweigh problems. Though it is untenable to argue against the use of evidence in policy-making, we are uncomfortable with an emerging policy framework based on such a narrow understanding of accountability and science. Current accountability regimes underpinning evidence-based policy instill performativity and foster performance management at the expense of professional responsibility. As Biesta (2004, p. 250) observes: "against this background I am inclined to conclude that the culture of accountability ultimately makes relationships of responsibility impossible." Proponents of evidence-based policy seem to ignore the importance of the neo-liberal origins of the accountability culture. What matters is what works. As a result they minimize the effect of control that is imposed by narrow interpretations of scientific evidence. Lather (2004) accuses governments adopting evidence-based policies based on experimental science of creating a technology of control in their attempts to define and determine proper scientific method. Scientific research conducted in a qualitative paradigm seems to count for nothing. Davies $(2005$, p. 2) takes the argument against evidence-based policy even further. He argues that the excessive use of evidence in the public sphere leads to an antagonistic relationship with democracy as "in an evidence-obsessed world, both politicians and public are able to renounce their responsibilities to the political process." Moreover, there are technical difficulties with evidence-based policy and practice. It is not value-free, 
is likely to give complex answers that are difficult to implement, results are often incomplete or equivocal, knowledge is advanced in miniscule steps and it cannot supply quick fixes. Philosophical and technical difficulties render problematic the notion that scientific evidence supporting a narrow accountability culture can improve student outcomes.

But does evidence-based policy and practice, dedicated to "what matters is what works", actually function to improve outcomes? Sanderson (2003), a cautious supporter of evidence-based policy, nevertheless fears that the evidence produced "will continue to provide limited purchase on causal mechanisms and present serious problems of external validity" (p. 342). It will fall short of expectations. The evidence we have sampled supports this. The results of evidence-based policy making are often uncertain or even problematic. For example, in the United States, Linn (2005) using a statistical modeling technique, found that valid and reliable inferences of whether measurable outcomes for reading and mathematics were achievable could not be made from the evidence base available. Yet, such evidence was used to assess institutional performance. Also using statistical modeling, Carnoy and Loeb (2004) studied the effect of evidence for accountability measures on a variety of policies including retention and progression. They found no significant evidence that American states with strong accountability regimes had better outcomes in retention and progression than states that did not. In the United Kingdom, Boaz and Pawson (2005) examined five research syntheses on the outcomes of mentoring for at-risk youth to determine how suitable findings would be as evidence for policy-makers. Their conclusions are cause for some pessimism. They found

... that many different viewpoints flow from the reviews. Indeed there is a whole range of incompatibilities and, at their heart, some seemingly contradictory advice on whether mentoring can be recommended for at-risk youth. (p. 176)

These three "case studies" do not sink the argument that outcomes will be improved by accountability regimes using evidence-based policy. They do, however, suggest that both statistical modeling and research syntheses must be treated with healthy skepticism. Regimes that punish institutions for not meeting evidence-based outcomes may be unfair.

If the process of evidence-based policy formation can be questioned using evidence from the United States and the United Kingdom, is there New Zealand evidence supporting a framework that attempts to improve student outcomes using an evidence-based accountability regime? We now use New Zealand retention research to explore more directly whether the proposed policy framework is indeed based on the available evidence. The TLRI study completed by Zepke at al. (2005) was neither experimental nor a research synthesis, though it built on an extensive synthesis of 146 international studies (Prebble et al., 2004). It used a research design that explored the experiences of stakeholders in seven tertiary institutions: two universities, four polytechnics/institutes of technology and a college of education. Moreover, it set out to identify what might work in New Zealand to improve retention, persistence and completion using the experiences of actors in the learning-teaching process. Proponents of evidence-based practice might question the results of survey research such as this. However, as Hedges (2001) points out, experimental and synthesis research are not always available and other research must stand in their place. As the TLRI study drew heavily on a research synthesis, this study seems to be an acceptable proxy for examining whether evidence supports the New Zealand policy framework.

The TLRI study used a holistic research design to seek the views of students, teachers and administrators on achieving student outcomes (Zepke et al., 2005). This article draws on one aspect of this design, a survey of 681 students enrolled for the first time in 2003. The sampling design posed an important methodological challenge: whether to use a national representative sample or gather and interpret the data as a series of seven case studies. The decision to follow a case study approach was supported by systematic reviews conducted by Braxton and Lien (2000) who found that empirical support for certain retention policies varied in strength and effect size for multi-institutional and single-institutional studies. Other retention researchers (Tinto, 1993; McInnis et al., 2000) also recommended that researchers undertake single institution case studies. Such investigations bring out single institutional factors that multi-institutional studies cannot identify. This view is supported from adult/tertiary teaching and learning research. Fenwick (2005), for example, identified as an important strand the view that education is situated practice. Rather than being located in some collective political, intellectual or pedagogical purpose, adult education is performed "in the habitual practices of a particular site or community" (p.9). This confirms that some answers to retention and achievement issues may be found more readily in data obtained from single institutions than from multi-institutional studies. 
Zepke, Leach and Prebble (2005) suggest that a case study approach may provide better evidence for improving student outcomes than a randomised experimental study. Their survey results support this contention and pose further questions about a national indicator-focused accountability regime to improve student outcomes. New Zealand results support Braxton and Lien's (2000) and McInnis et al.'s (2000) findings that individual institutions could face quite unique retention challenges; challenges that are obscured in multi-institutional studies. For example, a third of the respondents from one institution but only 9 percent in a second considered "quality of teaching" an important or very important reason for considering withdrawal. Reported as multi-institutional results, the percentage for all seven institutions for "teaching quality" was 20 percent, a figure which disguises information important to single institutions. Another key finding from this study was that the most important factor in students' decisions to withdraw was a non-institutional one - "there was too much going on in my life". Non-institutional factors are really important in both retention and success. Students overwhelmingly rated "I was really determined to succeed" as the most important factor in their continuing study. In three institutions it was rated important by over 80 percent of the students who kept studying after considering withdrawal. The authors comment "while it could be argued that claiming personal responsibility for persistence and success might be an expected response, the data are such that we cannot overlook the importance of this finding" (Zepke, Leach \& Prebble, in press).

This examination of outcomes policy in New Zealand has shown that the government and its agents seek research evidence to support policies to improve practice within a punitive accountability culture framed in neo-liberal terms. This, the paper suggests, raises a number of problems. Such a culture promotes performativity and performance management practices that inhibit relationships based on professionalism and democracy. It is also questionable that such policies actually work in improving student outcomes. In three international case studies cited in this paper, they did not, and the evidence from the New Zealand study discussed above suggests that such policies may run counter to achieving improved student outcomes such as retention and achievement, because they ignore individual institutional factors.

These findings are supported by those of Anae et al. (2002) who found that one factor influencing the success of Pasifika students included the type of institution they studied in: "One of the most significant findings from this group of participants is the different kind of learning experiences available through PTEs ... their focus on raising self-esteem and self-confidence levels as a basis for ongoing academic/ practical learning" (p. 86). Additional support comes from McInnis and James (2004, p. 43) who note "causes of non-completion ... are played in different ways across differentinstitutions". Scott (2005) adds another perspective. His findings show that in addition to differences between individual institutions, retention and completion rates are often affected by level of qualification being studied; being enrolled part-time rather than full-time; gender, ethnicity and age. In questioning the current policy framework, we do not imply that evidence-based policies or accountability should be abandoned. What we do suggest in the next section is that both terms should be re-framed.

\section{Re-framing Accountability and Evidence}

As noted above, following Biesta (2004), accountability has at least two distinct meanings. We would contend that the technical-managerial meaning dominates in New Zealand, and is the foundation of the current outcomes policy. It ensures that specified indicators are met via external audit and that institutions not meeting a normative standard eventually lose funding. The other meaning carries connotations of "being answerable to" - students, colleagues and, yes, governments for funding received. To be accountable in this sense, means working in relationships of mutual responsibility and trust (Codd, 1999). The emphasis on mutual responsibility is important. Accountability theorized in such terms results in: negotiation of goals, standards and their evaluation; in discussions about means and processes; in greater democracy. Distance between the various actors on the educational stage is reduced. Again following Biesta (2004), this view of accountability abandons the impersonal and distant relationships prevalent under its technical-managerial meaning while reclaiming the political dimension of accountability - the "taking responsibility for that which is of common concern" (p. 250).

Lather (2004, p. 765) characterises the current emphasis on science-based research as "militantly empiricist" with its claims that evidence must produce findings that are verifiable, definitive, cumulative, generalisable and immediately applicable to the policy arena. We agree with Sanderson (2003), who argues that this kind of evidence is indicative of an instrumental rationality, a narrow and limiting concept of both science and evidence. In pursuing only "what 
works", policy researchers are liable to leave to others such vital tasks as conceptualising ideas and issues, opening up the range of policy options available and challenging taken-for-granted assumptions about appropriate methods. We suggest that scientific research can have a softer, more inclusive aspect. This includes the acceptance that scientific research is subjective and interpretable, always subject to debate and re-interpretation - a "field of strategic possibilities" (Foucault, cited in Lather, 2004, p. 765). This means that we must broaden the scope of research beyond the technical. Lather $(2004$, p. 767) puts it as follows:

I am arguing for a critical qualitative presence in the preparation of program evaluators and policy analysts in order that these areas can become useful in fuzzying the lines between both research and evaluation and also the lines between empirical research, politics, and the philosophical renewal of public deliberation.

Such reframing of the nature of accountability and research evidence would have some important consequences for outcomes policy in New Zealand. While the performance dialogue with institutions envisaged by the Ministry of Education would remain a feature in the process of improving student outcomes, it would not be based on whether an institution occupies a low position on an indicator-based performance ladder. Rather all institutions would accept their responsibility of improving student outcomes by engaging in a dialogic relationship with their stakeholders, including the government, while seeking evidence from a variety of research paradigms.

\section{References}

Anae, M., Anderson, H., Benseman, J., \& Coxon, E. (2002). Pacific peoples and tertiary education: Issues of participation. Report prepared for the Ministry of Education. Retrieved on 29/05/06 from:

www.minedu.govt.nz/web/downloadable/dl6828_v1/participation.pdf

Astin, A. (1993). What matters in college? Four critical years revisited. San Francisco: Jossey Bass.

Astin, A. (1997). The changing American college student: Thirty year trends, 1966-1996. The Review of Higher Education, 21(2), 115-135.

Ball, S. (1998) Big policies/small world: An introduction to international perspectives in education policy. Comparative Education, 34(2), 119-130.

Bennett, S., \& Flett, R. (2001). Te Hua o te Ao Maori. He Pukenga Korero: A Journal of Maori Studies, 6(2), 29-34.
Braxton, J. (2000). Introduction. In J. Braxton. (Ed.), Reworking the student departure puzzle (pp. 1-8). Nashville: Vanderbilt University Press.

Braxton, J., \& Lien, L. (2000). The viability of academic integration as a central construct in Tinto's interactionalist theory of college student departure. In J. Braxton. (Ed.), Reworking the student departure puzzle (pp. 11-28). Nashville: Vanderbilt University Press.

Biesta, G. (2004). Education, accountability, and the ethical demand: Can the democratic potential of accountability be regained? Educational Theory, 54(3), 233-250.

Black, N. (2001). Evidence based policy: Proceed with care. British Medical Journal, 323, 275-279. Retrieved on 19/12/05 from

<http://bmj.bmjjournals.com/cgi/content/full/323/7307/725>

Boaz, A., \& Pawson, R. (2005). The perilous journey from evidence to policy: Five journeys compared. Journal of Social Policy, 34(2), 175-194.

Carnoy, M. \& Loeb, S. (2004). Does external accountability affect student outcomes? A cross-state analysis. In S. Fuhrman \& R. Elmore. (Eds), Redesigning accountability systems for education (pp. 189-219). New York: Teachers College Press.

Charlton, B. (2002). Audit, accountability, quality and all that: The growth of managerial technologies in UK universities. In S. Prickett \& P. Erskine-Hill (Eds.), Education! Education! Education! Managerial ethics and the law of unintended consequences (pp.18-28). Exeter: Imprint Academic.

Codd, J. (1999). Educational reform, accountability and the culture of distrust. New Zealand Journal of Educational Studies, 34(1), 45-53.

Codd, J. (2002). The Third Way for Tertiary Education Policy: TEAC and Beyond. New Zealand Annual Review of Education, 11, 31-57.

Codd, J. (2005). Introduction: Is there a third way for education. In J. Codd \& K. Sullivan. (Eds), Education policy directions in Aotearoa New Zealand (xiii-xviii). Southbank, Victoria: Thomson Dunmore Press.

Coe, R., Fitz-Gibbon, C., \& Tymms, P. (2000). Promoting evidence-based education: The role of practitioners. Round table presented at the British Educational Research Association Annual Conference. Retrieved on 17/12/2005 from <www.leeds.ac.uk/educol >

Coltman, D. (2005, July). New Zealand Education System: A comparative analysis of practices and strategies for traditionally underrepresented 
students. Paper presented at the Kellog Institute Appalachian State University.

Davies, W. (2005). Evidence-based policy and democracy. Open Democracy: Free thinking for the world. Retrieved on 19/12/2005 from $<$ www.openDemocracy.net $>$

Davies, H., \& Nutley, S. (2001, July). Evidence-based policy and practice: Moving from rhetoric to reality. The International, Interdisciplinary Evidence-based Policies and Indicator Systems Conference (pp. 86-95). Durham: University of Durham, The Curriculum, Evaluation and Management Centre (CEM).

Dewart, B. (2003). Towards a model for student retention. Unpublished paper. Palmerston North: Universal College of Learning.

Edwards, R., \& Usher, R. (2000). Globalisation and pedagogy. Space, place and identity. London: Routledge Falmer.

Fenwick, T. (2005, June). The audacity of hope - Towards poorer pedagogies. Keynote address to the Centre for Lifelong Learning Conference, Stirling, Scotland.

Finger, M., \& Asún, J. (2001). Adult education at the crossroads: Learning our way out. London: Zed Books.

Fitz-Gibbon, C. (1996). Monitoring education: Indicators, quality and effectiveness. London: Cassell.

Fraser, C. (2004, November). Setting and assessing entry criteria: To do or not to do? Building bridges: Diversity in practice. Proceedings of the Association of Tertiary Learning Advisers of Aotearoa/New Zealand Conference (ATLAANZ), New Plymouth, New Zealand.

Gerritson, J. (2005). Tertiary drop out rates revealed. New Zealand Education Review, 10(26), 1.

Grote, B. (2000). Student retention and support in open and distance learning. Lower Hutt: The Open Polytechnic of New Zealand.

Hedges, L. (2001). How can survey research contribute to evidence-based social policy? Third International, Inter-disciplinary Evidence-Based Policies and Indicator Systems Conference. Retrieved on 12/12/05 from < http://cem.dur.ac.uk>

Kelsey, J. (2002). At the crossroads: Three essays. Wellington: Bridget Williams Books.

Lather, P. (2004). Scientific research in education: A critical perspective. British Educational Research Journal, 30(6), 759-772.
Linn, R. (2005). Scientific evidence and inference in educational policy and practice: Implications for evaluating adequate yearly progress. In C. Dwyer (Ed.), Measurement and research in the accountability era. (pp. 21-30). Mahwah, NJ: Lawrence Erlbaum Associates.

Maharey, S. (2004). New measure gives students a voice in tertiary education. Media Statement October 29. Retrieved on 09/01/06 from <www.minedu.govt.nz/web/downloadable/d18754_v1/performance -measure-2910041.doc $>$

Martinez, P., \&. Munday, F. (1998). 9,000 voices: Student persistence and drop-out in further education. Further Education Development Agency Report, 2 (7). London: Further Education Development Agency.

McInnis, C., Hartley, R., Polesel, J., \& Teese, R. (2000). Non-completion in vocational education and training and higher education: A literature review. Canberra: Department of Employment, Education, Training and Youth Affairs (DEETYA).

McInnis, C., \& James, R. (2004). Access and retention in Australian higher education. In M. Yorke \& B. Longden (Eds.), Retention and student success in higher education (pp. 32-45). Maidenhead, UK: The Society for Research into Higher Education and Open University Press.

Ministry of Education. (2002). Interim funding policy 2002. Retrieved on 09/01/06 from:

$<$ www.minedu.govt.nz/index.cfm?layout=document\&documentid $=6502 \&$ data $=1>$

Ministry of Education (2003). Statement of intent 2003 - 2008.

Retrieved on 10/01/06 from $<$ www.minedu.govt.nz/index.cfm?layout=document\&documentid $=1$

Ministry of Education. (2004). Statement of intent 2004-2009. Retrieved on 10/01/06 from: $<$ www.minedu.govt.nz/web/downloadable/d19644_v1/soi---20042009.pdf $>$

Ministry of Education. (2005). Statement of intent 2005-2010. Retrieved on 10/01/06 from:

$<$ www.minedu.govt.nz/web/downloadable/d110361_vi/statement -of-intent-2005---2010.pdf

New Zealand Government. (2002). Tertiary education strategy 2002/07. Wellington: New Zealand Government. 
New Zealand Government. (2005). Statement of tertiary education priorities 2005-2007. Wellington: Office of the Minister of Education.

Olssen, M. (2001). The neo-liberal appropriation of tertiary education policy in New Zealand: Accountability, research and academic freedom. New Zealand Association of Research in Education (NZARE) "State-of-the-Art" Monograph No 8. Palmerston North: NZARE

Peters, M., \& Marshall, J. (1996). The politics of curriculum: Busnocratic rationality and enterprise culture. Delta, 48(1), 33-46.

Pascarella, E., \& Terenzini, P. (1991). How college affects students: Findings and insights from twenty years of research. San Francisco: Jossey Bass.

Pascarella, E., \& Terenzini, P. (2004). How college affects students: A third decade of research (Vol. 2). San Francisco: Jossey Bass.

Prebble, T., Hargraves, H., Leach, L., Naidoo, K., Suddaby, G., \& Zepke, N. (2004). Impact of student support services and academic development programmes on student outcomes in undergraduate tertiary study: A synthesis of the research. New Zealand Ministry of Education. Retrieved on 12/12/05 from:

$<$ www.minedu.govt.nz/index.cfm?layout=document\&documentid $=10247 \&$ data $=1$

Petrosino, A., Boruch, R., Soydan, H., Duggan, L., \& Sanchez-Meca, J. (2001). Meeting the challenges of evidence-based policy: The Campbell collaboration. ANNALS of the American Academy, 578, 14-34.

Purnell, S. (2002). A map, a bicycle and good weather: The transition to undergraduate study. Unpublished MEd thesis, Massey University, Wellington.

Sanderson, I. (2003). Is it "what works" that matters? Evaluation and evidence-based policy-making. Research Papers in Education, 18(4), 331-345.

Scott, D. (2005). Retention, completion and progression in tertiary education in New Zealand. Journal of Higher Education Policy and Management, 27(1), 3-17.

Sector Reference Group to the Ministry of Education and the Tertiary Commission. (2004). Developing a performance-based element in tertiary education funding for teaching and learning. Retrieved on 09/01/06 from $<$ www.minedu.govt.nz/web/downloadable/d19676 v1/srg-report--final-for-release.da $>$
Technical Working Group. (2003). Introduction of a performance element to tertiary education funding. Retrieved on 09/01/06 from

$<$ www.minedu.govt.nz/web/downloadable/d19685_v1/report-pdf ---amended.pdf>

Tertiary Education Advisory Commission,. (2001). Shaping the system. Second report of the Tertiary Education Advisory Commission. Wellington: New Zealand Government.

Tinto, V. (1975). Dropout from higher education: A theoretical synthesis of recent research. Review of Educational Research, 45(1), 89-125.

Tinto, V. (1988). Stages of student departure: Reflections on the longitudinal character of student leaving. Journal of Higher Education, $59(4), 438-455$.

Tinto, V. (1993). Leaving college: Rethinking the causes and cures of student attrition (2nd Ed.). Chicago: The University of Chicago Press.

Trembath, V. (2004). "Finally it was all too much": Reasons for leaving early from initial teacher education. Unpublished MEd thesis, Auckland College of Education, Auckland.

Wilson, S. (2002, September). Retention and success: A practical approach. Paper presented at the Adult Learning Conference, Wellington.

Wilson, S. (2005, August). Why students succeed: WELTEC students' views. Wellington Institute of Technology Research seminar.

Yorke, M. (1999). Leaving early: Undergraduate non-completion in higher education. London: Falmer Press.

Yorke, M., \& Longden, B. (2004). Retention and student success in higher education. Maidenhead, UK: The Society for Research into Higher Education and Open University Press.

Zepke, N., \& Leach, L. (2005). Integration and adaptation: Approaches to the student retention and achievement puzzle. Active Learning in Higher Education, 6(1), 46-59.

Zepke, N., Leach, L., \& Prebble, T. (2005). Now you have got them how do you keep them? Factors that influence student departure and persistence. New Zealand Journal of Educational Studies, $40(1$ \& 2), 181-199.

Zepke, N., Leach, L., Prebble, T., Henderson, J., Leadbeater, J., Solomon, N. \& Wilson, S. (2005, December). Improving tertiary student outcomes in their first year of study. Paper presented at the Teaching and Learning Research Initiative Symposium, NZARE Conference, Dunedin. 


\section{The authors}

Nick Zepke is an Associate Professor in the College of Education at Massey University with research interests that focus on futures and policy studies, assessment, student retention and the scholarship of teaching. He has recently published a number of articles on retention, attrition and completion of tertiary students, for example, the final report on a recent Teaching and Learning Research Initiative project Improving Tertiary Student Outcomes in the First Year of Study:

$<$ www.tlri.org.nz/pdfs/NickZepkefullreport.pdf>

Linda Leach is a Senior Lecturer in the Massey University College of Education, Palmerston North. She has worked in formal and non-formal adult education for over twenty years and currently teaches in undergraduate and postgraduate programmes. Her research interests include adult learning and teaching, assessment and tertiary student retention. She was a joint project leader, with Nick Zepke and Tom Prebble, of a two year Teaching and Learning Research Initiative project Improving Tertiary Student Outcomes in the First Year of Study. 